This item was submitted to Loughborough's Research Repository by the author.

Items in Figshare are protected by copyright, with all rights reserved, unless otherwise indicated.

\title{
Listening to infrastructure, EPSRC fellowship
}

PLEASE CITE THE PUBLISHED VERSION

https://doi.org/10.21820/23987073.2018.5.25

\section{PUBLISHER}

Science Impact Ltd

VERSION

VoR (Version of Record)

\section{PUBLISHER STATEMENT}

This work is made available according to the conditions of the Creative Commons Attribution 4.0 International (CC BY 4.0) licence. Full details of this licence are available at: http://creativecommons.org/licenses/ by/4.0/

\section{LICENCE}

CC BY-NC-ND 4.0

\section{REPOSITORY RECORD}

Smith, Alister. 2019. "Listening to Infrastructure, EPSRC Fellowship". figshare. https://hdl.handle.net/2134/34931. 


\section{Impact Objectives}

- Develop new low-cost autonomous sensing technologies for asset condition appraisal and real-time communication of deterioration

$\bullet$

- Improve infrastructure health monitoring capability and transform geotechnical asset management

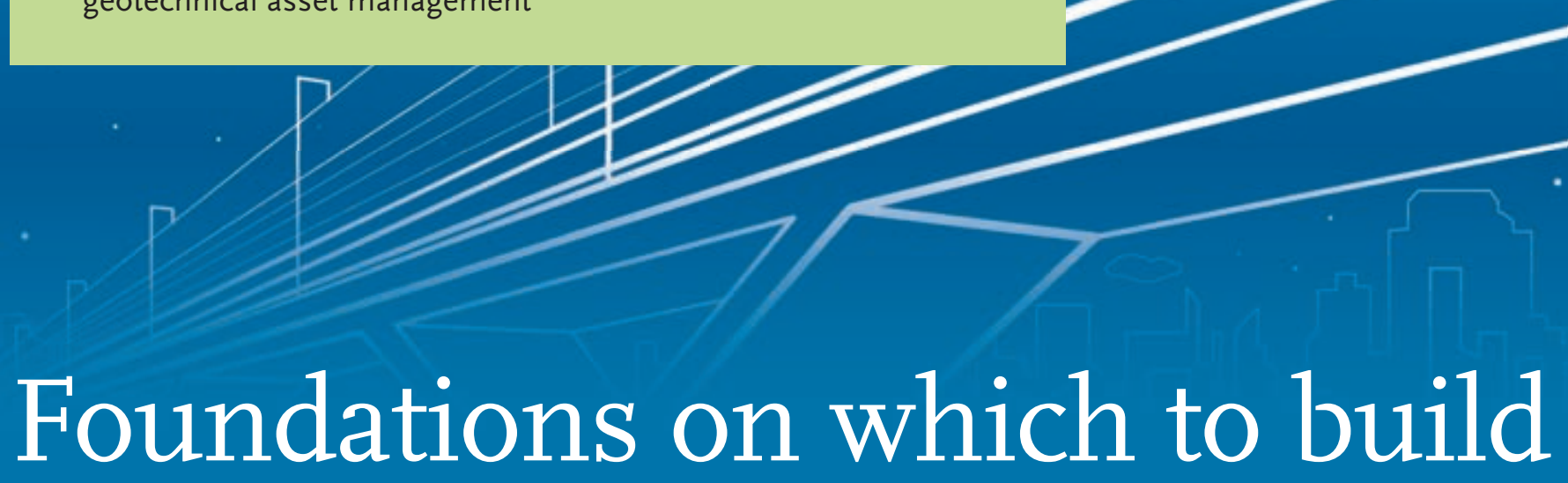

Dr Alister Smith is the Principal Investigator of a project that seeks to develop new and improved infrastructure health monitoring capability. Here, he introduces his research and how he will translate his findings into real-world deployment

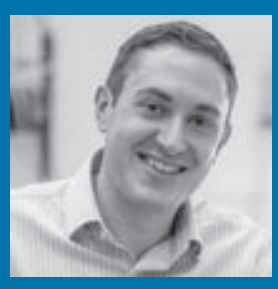

First, can you tell us about your academic training?

As an undergraduate civil engineer, I developed a keen interest in geotechnical engineering because it deals with highly variable particulate materials, such as the soils in the ground, and combines the mechanics of both solids and fluids. My PhD was in geotechnical engineering and developed an approach to quantify slope deformation behaviour using acoustic emission (AE) monitoring, continuously and in real-time, which can now be used to provide early warning of landslides.

How did you come to develop an interest in civil engineering, particularly in relation to infrastructure and asset management?

Through the work mentioned above, I became fascinated by the need to measure the behaviour of assets and understand how they are performing in real-time. I rapidly became aware that the AE monitoring approach has vast potential applications in monitoring the performance of many different geotechnical assets (e.g. buried pipes, pile foundations, retaining walls, tunnel linings, rail track, earth dams and levees), which led to me developing a new area of research: Listening to Infrastructure.

What are the aims and intended outcomes of the Listening to Infrastructure project?

The long-term vision for Listening to Infrastructure is to transform geotechnical asset management by developing new, lowcost, autonomous AE sensing technologies for condition appraisal and real-time communication of deterioration. My current UK Engineering and Physical Sciences Research Council (EPSRC) Fellowship is for three years and has specific aims and intended outcomes to make a significant step towards achieving that vision.

In what ways does Listening to Infrastructure build upon your previous research on Slope ALARMS?

Slope ALARMS (www.slopealarms.com) is a project that has been led by Professor Neil Dixon over several years to develop an AE landslide early warning system. Early warning systems for slope instability need to alert users of accelerating slope deformation behaviour to enable evacuation of vulnerable people and timely repair and maintenance of critical infrastructure. However, currently available warning systems are prohibitively expensive or have technical limitations.

The AE monitoring approach using active waveguides had the potential to be an affordable warning system, but no strategies existed to interpret/quantify slope deformation behaviour from the measured AE. For my PhD I used theoretical, physical model and field experiments to develop a framework and algorithm to quantify slope displacement rates from measured $A E$, continuously and in real-time. Slope ALARMS can now provide an early warning of landslides by detecting, quantifying and communicating accelerations in slope movement. We have now licensed Slope ALARMS (and Community Slope SAFE, an even lower cost landslide warning system for use by vulnerable communities) to RST Instruments Ltd. (www.rstinstruments. com), who will further develop, manufacture and distribute the sensors worldwide, maximising economic and societal impact.

How will you ensure your research findings translate into real-world deployment and commercialisation?

Early and sustained engagement with end-users is ensuring that the research is informed by end-user needs and expectations, and that end-users are aware of - and upto-date with - the research developments. Performing full-scale field-testing with inservice assets will demonstrate performance and benefits in intended applications and environments, and will progress the research through Technology Readiness Levels. It is envisaged that commercialisation will happen through licensing of Intellectual Property to a technology provider (or providers) that offers products to appropriate end-users, which will follow a comparable commercialisation model to the one we have already undertaken with Slope ALARMS. 


\section{The future of infrastructure}

\section{is sound}

With a focus on acoustic emission generated by geotechnical assets, the Listening to Infrastructure project aims to provide an early warning of deterioration of infrastructure materials and systems in real-time

Given that much of what we rely on to live the lives we do is situated underground, you could be forgiven for not fully realising just how important infrastructure is to our quality of life. Tunnels, train tracks, foundations, pipelines, sea walls and dams are all examples of infrastructures that enable us to do an enormous amount of things that are vital to modern life.

Existing infrastructure is rapidly deteriorating the rate of which is accelerating with increasing pressures from climate change and population growth - and the condition of most assets is unknown. Improved assessment and monitoring capability is urgently needed to ensure that the performance of infrastructure can be maintained and be resilient to uncertain future conditions.

\section{ACOUSTIC EMISSION}

It is with the above in mind that the Listening to Infrastructure project has been

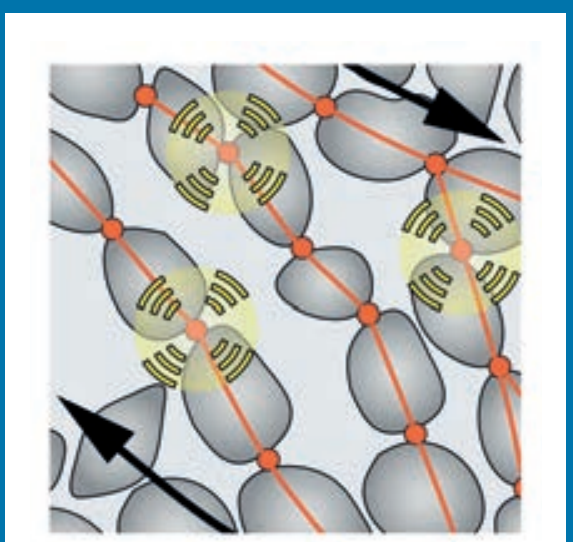

$A E$ generated by soil deformation

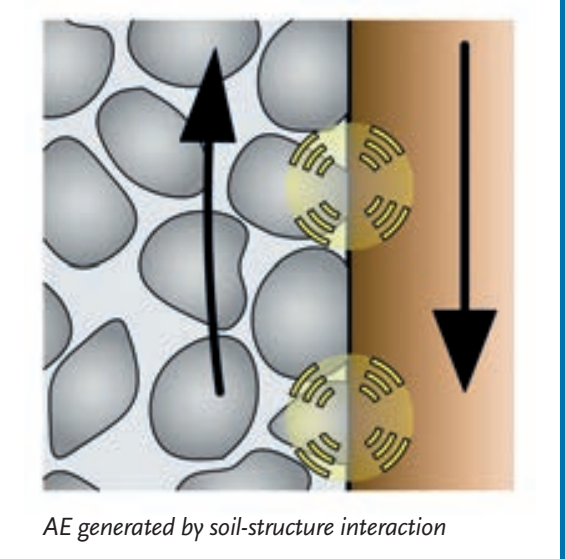

established. The lead research organisation behind this three-year project is Loughborough University, UK, with Dr Alister Smith serving as the Principal Investigator. The research is central to the Engineering and Physical Sciences Research Council's priority area of Engineering for Sustainability and Resilience, with the primary goal being to develop new monitoring technology that could revolutionise infrastructure stewardship.

Acoustic emission (AE) is at the centre of the investigations, with good reason. 'AE is highfrequency noise, which typically propagates at superaudible frequencies (i.e. at frequencies higher than the human ear can detect). When materials are subject to a change in stress they respond by deforming, and some energy is in the form of heat and sound,' explains Smith. 'The idea behind AE monitoring is to detect, measure and interpret this sound energy to understand what is happening inside a material.'

One example where AE is particularly useful can be found in the development of a crack in steel or rock. As the crack develops, some of the energy released propagates as AE stress waves. These waves can be measured to monitor the integrity of the materials, thereby providing researchers and engineers with a means to understand the extent of the problem. Such methods have been used across a range of industries for a number of years, but are not widely used in geotechnical engineering because it is extremely difficult to interpret the AE that is generated by soils, which are highly variable particulate materials and generate $A E$ through inter-particle friction. 'Detection of AE is the centre of my investigation because this challenge is exciting,' explains Smith. 'If we can listen to geotechnical assets with intelligent sensors - analogous to a stethoscope being used to listen to a patient's heartbeat - we will be able to provide information on the condition of infrastructure and early warning of deterioration in real-time.'

\section{REDUCING DAMAGE, SAVING LIVES,} LIMITING COSTS

It is worth highlighting that, while some instruments and techniques to monitor geotechnical assets do already exist, they tend to have technical limitations or to not be cost-effective. In addition, adopting conventional approaches paints an incomplete picture that too heavily relies on providing localised information on deformations or groundwater at discrete time intervals. While such instruments and techniques have their uses, continuous monitoring is required, as this provides important information on the condition of assets throughout their lifecycle. In this way, planning for the future is made possible, as researchers and engineers can truly understand the longevity of existing infrastructure and react accordingly.

Using $A E$ as a method is particularly exciting as, by increasing understanding of how assets are deteriorating, better design approaches can be taken from the outset. 'AE will enable us to extract more information about asset condition than existing techniques,' enthuses Smith. 'Not only deformation behaviour, but also, for example, changes in stress states and transitions from pre- to post-peak shear strength. By using correlation techniques, it will be possible to locate the source of AE to target maintenance and remediation activities.'

\section{AE sensing will also provide real-time} warnings to enable safety-critical decisions to be made. Importantly, this will reduce damage, injury and loss of life. In addition, because the number of asset monitoring locations required per unit length to achieve sufficient spatial resolution will be less than other monitoring techniques, the novel technologies will come at a significantly lower cost.

\section{IN ITS INFANCY}

The Listening to Infrastructure project began in July 2017 and the primary focus for the first year has been element testing in the laboratory. 'I have developed an AE data acquisition system and associated software to detect, measure and process the $\mathrm{AE}$ generated by samples during experiments,' explains Smith. 'I am currently in the middle of two testing programmes. The first is triaxial shear testing on a range of soils with different properties - these tests subject samples of soil to representative in-ground 
